\title{
Prevalence and risk factors for Toxoplasma gondii infection among pregnant and postpartum women attended at public healthcare facilities in the City of Niterói, State of Rio de Janeiro, Brazil
}

\author{
Fernanda Loureiro de Moura ${ }^{[1]}$, Maria Regina Reis Amendoeira ${ }^{[2]}$, \\ Otílio Machado Pereira Bastos ${ }^{[1]}$, Danuza Pinheiro Bastos Garcia de Mattos ${ }^{[1]}$, \\ Ana Beatriz Monteiro Fonseca ${ }^{[3]}$, José Leonardo Nicolau ${ }^{[2],}$ \\ Leandro Baptista das Neves ${ }^{[2]}$ and Patricia Riddell Millar ${ }^{[1],[2]}$
}

[1]. Departamento de Microbiologia e Parasitologia, Universidade Federal Fluminense, Niterói, RJ. [2]. Laboratório de Toxoplasmose, Instituto Oswaldo Cruz, Fundação Oswaldo Cruz, Rio de Janeiro, RJ. [3]. Departamento de Estatística, Universidade Federal Fluminense, Niterói, RJ.

\begin{abstract}
Introduction: To determine the prevalence of immunoglobulin $\mathrm{G}(\operatorname{IgG})$ and immunoglobulin $\mathrm{M}(\operatorname{IgM})$ anti-Toxoplasma gondii antibodies among pregnant and postpartum women attended within the public healthcare system in Niterói, State of Rio de Janeiro, and to detect possible exposure factors associated with T. gondii infection in this population. Methods: IgM and IgG anti- T. gondii antibodies were investigated in 276 pregnant and 124 postpartum women by using the indirect immunofluorescence (IFAT) and immunoenzymatic assay (ELISA) techniques. The participants were selected by convenience sampling. All these 400 patients filled out a free and informed consent statement, answered an epidemiological questionnaire and were informed about the disease. Results: Among the 400 samples analyzed, 234 (58.5\%) were reactive to IgG anti-T. gondii antibodies, according to the IFAT and/or ELISA assay. One pregnant woman was found to be reactive to IgM anti- $T$. gondii antibodies, with an intermediate IgG avidity test. Risk factor analysis showed that seropositivity was significantly associated $(p<0.05)$ with age, contact with cats and presence of rodents at home. Through a logistic regression model, these associations were confirmed for age and contact with cats, while education at least of the high school level was found to be a protective factor. Conclusions: The prevalence rate of IgG anti-T. gondii antibodies in the City of Niterói was high and the risk factors for infection detected after multivariate analysis were: age over 30 years, contact with cats and education levels lower than university graduate level.
\end{abstract}

Keywords: Toxoplasma gondii. Pregnant women. Postpartum women. Seroprevalence.

\section{INTRODUCTION}

Toxoplasmosis is a zoonosis caused by the obligate intracellular parasite Toxoplasma gondii, which infects warm-blooded animals, including human beings, and is found in almost every country, of various climates and social conditions, with variable levels in the percentage of positive tests $^{1,2}$. Congenital toxoplasmosis results mainly from primary maternal infection during pregnancy ${ }^{3}$, but can occasionally result from preconceptional infection or reactivation of latent infection in immunodeficient pregnant women, or even in immunocompetent women who were previously immune ${ }^{4}$. Transmission of $T$. gondii to the fetus can result in serious health problems including mental retardation, seizures, blindness and

Address to: Dra. Patricia Riddell Millar. Depto. Microbiologia e Parasitologia/ Instituto Biomédico/UFF. Rua Professor Hernani Melo 101, São Domingos, 24210-130 Niterói RJ, Brasil.

Phone: 5521 2629-2424; 5521 2629-2425.

e-mail: patriciariddell@vm.uff.br

Received 18 April 2012

Accepted 28 February 2013 death. Some health problems may not become apparent until the second or third decade of life $\mathrm{e}^{5-7}$.

This infection is widespread around the world, in different countries and geographical areas within the same country and in different ethnic groups living in the same area ${ }^{8-14}$. Thus, over the past three decades, antibodies anti- $T$. gondii have been detected in various adult human populations in proportions ranging from 9.1 to $97.4 \%$ of these individuals ${ }^{15,16}$. In Brazil, studies on pregnant and/or postpartum women have indicated different prevalences in different states within the country ${ }^{17-24}$, which adds to the importance of studying toxoplasmosis.

Risk factors for $T$. gondii infection are associated with hygiene, dietary and other cultural habits and climate ${ }^{18}$. According to infection routes and potential exposure, the most prevalent risk factors for toxoplasmosis are: deficiencies in environmental sanitation (untreated water), presence of domestic cats and rodents, consumption of potentially contaminated food (raw or undercooked meat and insufficiently washed vegetables) and contact with contaminated soil ${ }^{25}$.

The aims of the present study were to determine the prevalence of immunoglobulin $\mathrm{G}(\mathrm{IgG})$ and immunoglobulin $\mathrm{M}$ 
(IgM) anti-T. gondii antibodies among pregnant and postpartum women attended within the public healthcare system in Niterói, Rio de Janeiro, and to detect possible exposure factors associated with $T$. gondii infection in this population.

\section{METHODS}

A cross-sectional study was carried out among 276 pregnant and 124 postpartum women who received prenatal care between September 2010 and September 2011, through the public healthcare system in Niterói, State of Rio de Janeiro, in order to determine the prevalence of IgG and IgM anti- $T$. gondii antibodies. The study was conducted in the maternity outpatient clinic at the Hospital Universitário Antonio Pedro (the university hospital) of Universidade Federal Fluminense (HUAP/UFF), Policlínica Comunitária Sergio Arouca (PCSA; a community polyclinic) and five Family Doctor Program units (Viradouro, Preventório I and II, Palacio and Souza Soares). Among the volunteers, there were 300 (75\%) from HUAP/UFF, 67 (16.8\%) from PCSA and 33 (8.2\%) from the Family Doctor Program units. The Hospital Universitário Antônio Pedro is a referral hospital for high-risk pregnancy, and receives patients living in Niterói as well as in other neighboring cities, such as São Gonçalo, Maricá and Itaboraí, among others. The Family Doctor Program units and the Policlínica Comunitária Sergio Arouca provide prenatal care for low-risk patients who live in specified regions of Niterói. Thus, each unit has its own area of activity and number of registered families. The people who use these services are characterized mostly by low educational level, financial difficulties and absence of adequate sanitary conditions.

All the 400 patients filled out a free and informed consent statement. Serum samples were collected, and then the patients answered an epidemiological questionnaire and received information about the disease. These samples were stored at $-20^{\circ} \mathrm{C}$ until they were assayed. The questionnaires were applied at face-to-face interviews by the researchers, who provided guidance about the proposed research and read out the consent form, which the interviewees then signed. The questions were answered orally by the interviewees and recorded by the researchers, so that the study participants would find it easier to understand the subject matter. After this stage, guidance on T. gondii infection was provided with special emphasis on the ways of preventing infection. Because the participant's name was written on the questionnaire and the serological results were subsequently sent to each participant, the risk of interviewing the same person twice was eliminated.

$\operatorname{IgG}$ and $\operatorname{IgM}$ anti- $T$. gondii antibodies were analyzed by means of the indirect fluorescent antibody test (IFAT) with a cutoff point of 1:16; and ELISA (BioKit ${ }^{\circledR}$, Barcelona, Spain), in which readings at or above the cutoff value were considered positive. The tests were performed at the Toxoplasmosis Laboratory (LABTOXO) of the Oswaldo Cruz Institute (IOC/FIOCRUZ). Participants were selected by convenience sampling. Postpartum women between the first and tenth day's postpartum and pregnant women at any gestational age were eligible. On the other hand, women taking immunosuppressive drugs and those who did not agree to sign the consent statement were excluded. In cases of positive IgM samples, IgG avidity for $T$. gondii was tested at the Evandro Chagas Clinical Research Institute, Fiocruz. The test was performed on the fully automated VIDAS system (VIDAS Toxo-IgG Avidity®, BioMérieux, Marcy-l'Etoile, France). The results were interpreted as recommended by the manufacturer, as follows: < 4IU ml-1, negative; 4-8 IU ml-1, borderline; > 8IU ml-1, positive. The results were given to the physician responsible for the patients' prenatal care, for follow-up purposes and so that treatment could be started if necessary. A simple ratio was used to estimate seropositivity for toxoplasmosis among pregnant and postpartum women. Univariate relationships between a diagnosis of toxoplasmosis and the factors of interest were studied using the chi-square test. All the significant variables were included in a multivariate analysis, in which a multiple logistic regression model was used. The results from the logistic regression were expressed as odds ratios (OR) and the corresponding 95\% confidence interval $(95 \% \mathrm{CI})$. Adjusted odds ratios were calculated and their statistical significance was evaluated in accordance with the Wald test. A significance level of 0.05 was used to denote statistical significance. The data were analyzed using the Statistical Package for the Social Sciences 10.0 (SPSS) computer software.

The copositivity and conegativity rates and the concordance of the tests were determined as described by Teva, Fernandez and Silva ${ }^{26}$. The Kappa index was used to measure the real agreement between the serological techniques.

\section{Ethical considerations}

The present study was approved by the Ethics Committee for Research on Human Beings of Universidade Federal Fluminense and Hospital Universitário Antonio Pedro, through document number 078/2010 and CAAE number 0059.0.258.000-10, in accordance with Resolution 196/96 of the National Health Council.

\section{RESULTS}

The Kappa value for concordance between the two techniques for detection of IgG against $T$. gondii was 0.89 , which reflects almost perfect agreement between the two techniques, as described by Teva, Fernandez and Silva ${ }^{26}$. Furthermore, for detection of IgM against $T$. gondii, the Kappa was 0.2 which is considered to be a fair level of agreement.

In the data analysis, samples that were reactive in the IFAT and/or ELISA test were taken into consideration, thus totaling $234(58.5 \%)$ samples that were reactive to IgG anti-T. gondii 
TABLE 1 - Analysis of the biological and educational variables associated to the presence of IgG anti-Toxoplasma gondii antibodies in pregnant and postpartum women attended at public health system in Niterói, State of Rio de Janeiro, Brazil, 2010-2011

\begin{tabular}{|c|c|c|c|c|c|c|c|c|c|}
\hline \multirow[b]{3}{*}{ Variables } & \multirow{2}{*}{\multicolumn{2}{|c|}{$\begin{array}{c}\text { Reactive } \\
\text { IgG }\end{array}$}} & \multirow{2}{*}{\multicolumn{2}{|c|}{$\begin{array}{c}\text { Non-reactive } \\
\qquad \operatorname{IgG}\end{array}$}} & \multirow{2}{*}{\multicolumn{2}{|c|}{ Total }} & \multirow[b]{3}{*}{$\mathrm{OR}$} & \multirow[b]{3}{*}{$95 \% \mathrm{CI}$} & \multirow[b]{3}{*}{$\mathrm{p}$} \\
\hline & & & & & & & & & \\
\hline & $\mathrm{n}$ & $\%$ & $\mathrm{n}$ & $\%$ & $\mathrm{n}$ & $\%$ & & & \\
\hline \multicolumn{10}{|l|}{ Age group (years) } \\
\hline $14-20 *$ & 40 & 43.5 & 52 & 56.5 & 92 & 100.0 & & & \\
\hline $31-45$ & 81 & 66.9 & 40 & 33.1 & 121 & 100.0 & 2.63 & $1.50-4.60$ & \\
\hline total & 234 & 58.5 & 166 & 41.5 & 400 & 100.0 & & & \\
\hline \multicolumn{10}{|l|}{ Education } \\
\hline incomplete basic education* & 77 & 65.3 & 41 & 34.7 & 118 & 100.0 & & & \\
\hline incomplete university degree & 8 & 47.1 & 9 & 52.9 & 17 & 100.0 & 0.47 & $0.17-1.31$ & \\
\hline complete university degree & 5 & 33.3 & 10 & 66.7 & 15 & 100.0 & 0.26 & $0.08-0.83$ & \\
\hline total & 234 & 58.5 & 166 & 41.5 & 400 & 100.0 & & & \\
\hline \multicolumn{10}{|l|}{ Abortion } \\
\hline yes & 59 & 64.1 & 33 & 35.2 & 92 & 100.0 & 1.35 & $0.83-2.20$ & 0.212 \\
\hline no & 175 & 56.8 & 133 & 43.2 & 308 & 100.0 & & & \\
\hline total & 234 & 58.5 & 166 & 41.5 & 400 & 100.0 & & & \\
\hline
\end{tabular}

*Reference category. OR: odds ratio; CI: confidence interval; IgG: immunoglobulin G.

antibodies, and 166 (41.5\%) samples that were susceptible to toxoplasmosis. Among the 234 positive samples, 161 (68.8\%) were from pregnant and 73 (31.2\%) from postpartum women. In the present study, we found no statistically significant difference $(p=0.919)$ in relation to seroprevalence among pregnant and postpartum women. Seventeen $(4.2 \%)$ samples were found to be reactive to IgM anti-T. gondii antibodies. One patient presented an intermediate result in the IgG avidity test, while the other patients showed high IgG avidity. The woman who had an intermediate result started treatment under supervision by the physician responsible for her case and remained under observation throughout her pregnancy. The newborn showed no signs or symptoms of congenital toxoplasmosis. This patient's umbilical cord blood was analyzed using ELISA (BioKit ${ }^{\circledR}$ ) and was found to be negative for IgM anti-T. gondii antibodies and positive for IgG anti-T. gondii antibodies. The relationship between serological profile, age, maternal education level and previous abortions is shown in Table 1. There was a linear trend of increasing proportion of seropositivity for toxoplasmosis with increasing age among the subjects $(\mathrm{p}=0.002)$. Completed basic education was not significantly associated $(\mathrm{p}=0.171)$ with seropositivity in the bivariate analysis. There was no significant association between previous abortions and seropositivity for toxoplasmosis $(\mathrm{p}=0.212)$.
The relationship between serological profile and possible risk factors for toxoplasmosis is shown in Table 2. There were significant associations between seropositivity for toxoplasmosis and contact with cats $(\mathrm{p}=0.039)$ and between seropositivity and presence of rodents at home $(\mathrm{p}=0.008)$. No significant association was found between seropositivity for toxoplasmosis and the other variables. There was no evidence of association with consumption of water from the public water supply $(\mathrm{p}=0.075)$ at the significance level of $5 \%$.

Multivariate analysis only confirmed the associations between seropositivity for toxoplasmosis and age group and between seropositivity and contact with cats. The odds of seropositivity among participants who reported contact with cats were 1.68 times higher than among those who had no contact with these animals. According to the OR of the age group variable, the chance that women in the range of 31 to 45 years old would be positive for toxoplasmosis was 3.97 times higher than for those who were outside this age group. The education variable significantly modified seropositivity for toxoplasmosis, such that education at least of the high school level was a protective factor against the infection (Table 3). The presence of rodents at home did not show any significant association $(\mathrm{p}>0.05)$ after multivariate analysis. 
TABLE 2 - Analysis of the alimentary, hygiene habits and behavior variables associated to the presence of IgG anti-Toxoplasma gondii antibodies in pregnant and postpartum women attended at public Health system in Niterói, State of Rio de Janeiro, Brazil, 2010-2011

\begin{tabular}{|c|c|c|c|c|c|c|c|c|c|}
\hline \multirow[b]{3}{*}{ Variables } & \multirow{2}{*}{\multicolumn{2}{|c|}{$\begin{array}{c}\text { Reactive } \\
\text { IgG }\end{array}$}} & \multirow{2}{*}{\multicolumn{2}{|c|}{$\begin{array}{c}\text { Non-reactive } \\
\text { IgG }\end{array}$}} & \multirow{2}{*}{\multicolumn{2}{|c|}{ Total }} & \multirow[b]{3}{*}{$\mathrm{OR}$} & \multirow[b]{3}{*}{$95 \% \mathrm{CI}$} & \multirow[b]{3}{*}{$\mathrm{p}$} \\
\hline & & & & & & & & & \\
\hline & $\mathrm{n}$ & $\%$ & $\mathrm{n}$ & $\%$ & $\mathrm{n}$ & $\%$ & & & \\
\hline \multicolumn{10}{|l|}{ Contact with cats } \\
\hline yes & 91 & 65.5 & 48 & 34.5 & 139 & 100.0 & 1.56 & $1.02-2.39$ & 0.039 \\
\hline no & 143 & 54.8 & 118 & 45.2 & 261 & 100.0 & & & \\
\hline \multicolumn{10}{|l|}{ Contact with soil } \\
\hline yes & 54 & 64.3 & 30 & 35.7 & 84 & 100.0 & 1.36 & $0.82-2.24$ & 0.226 \\
\hline no & 180 & 56.9 & 136 & 43.1 & 316 & 100.0 & & & \\
\hline total & 234 & 58.5 & & 166 & 41.5 & 400 & 100.0 & & \\
\hline no & 205 & 59.2 & 141 & 40.8 & 346 & 100.0 & & & \\
\hline total & 234 & 58.5 & 166 & 41.5 & 400 & 100.0 & & & \\
\hline \multicolumn{10}{|l|}{ Consumption of undercooked meat } \\
\hline yes & 70 & 55.1 & 57 & 44.9 & 127 & 100.0 & 0.81 & $0.53-1.24$ & 0.349 \\
\hline no & 164 & 60.1 & 109 & 39.9 & 273 & 100.0 & & & \\
\hline total & 234 & 58.5 & 166 & 41.5 & 400 & 100.0 & & & \\
\hline \multicolumn{10}{|l|}{ Consumption of embedded meat } \\
\hline yes & 200 & 57.8 & 146 & 42.2 & 346 & 100.0 & 0.80 & $0.44-1.45$ & 0.474 \\
\hline total & 234 & 58.5 & 166 & 41.5 & 400 & 100.0 & & & \\
\hline \multicolumn{10}{|l|}{ Water source } \\
\hline drinking water from public supply system & 187 & 60.9 & 120 & 39.1 & 307 & 100.0 & 1.52 & $0.95-2.43$ & 0.075 \\
\hline other sources (well water, mineral water bottles) & 47 & 50.5 & 46 & 49.5 & 93 & 100.0 & & & \\
\hline total & 234 & 58.5 & 166 & 41.5 & 400 & 100.0 & & & \\
\hline \multicolumn{10}{|l|}{ Presence of rats at home } \\
\hline yes & 98 & 67.1 & 48 & 32.9 & 146 & 100.0 & 1.77 & $1.15-2.70$ & 0.008 \\
\hline no & 136 & 53.5 & 118 & 46.5 & 254 & 100.0 & & & \\
\hline total & 234 & 58.5 & 166 & 41.5 & 400 & 100.0 & & & \\
\hline \multicolumn{10}{|l|}{ Garbage collection } \\
\hline public collection & 226 & 58.5 & 160 & 41.5 & 386 & 100.0 & 1.05 & $0.36-3.11$ & 0.916 \\
\hline other (buried, burned) & 8 & 57.1 & 6 & 42.9 & 14 & 100.0 & & & \\
\hline total & 234 & 58.5 & 166 & 41.5 & 400 & 100.0 & & & \\
\hline
\end{tabular}

OR: odds ratio; CI: confidence interval; IgG: immunoglobulin G. 
TABLE 3 - Risk factors for Toxoplasma gondii infection in pregnant and postpartum women attended at public health system in Niterói, State of Rio de Janeiro, Brazil, $2010-2011$. Final multivariate logistic regression model

\begin{tabular}{|c|c|c|c|c|c|c|c|c|c|}
\hline \multirow[b]{2}{*}{ Variables } & \multicolumn{2}{|c|}{$\begin{array}{c}\text { Reactive } \\
\text { IgG }\end{array}$} & \multicolumn{2}{|c|}{$\begin{array}{c}\text { Non-reactive } \\
\text { IgG }\end{array}$} & \multicolumn{2}{|c|}{ Total } & \multirow[b]{2}{*}{$\mathrm{OR}$} & \multirow[b]{2}{*}{$95 \% \mathrm{CI}$} & \multirow[b]{2}{*}{$\mathrm{p}$} \\
\hline & $\mathrm{n}$ & $\%$ & $\mathrm{n}$ & $\%$ & $\mathrm{n}$ & $\%$ & & & \\
\hline \multicolumn{10}{|l|}{ Age group (years) } \\
\hline $14-20^{*}$ & 40 & 43.5 & 52 & 56.5 & 92 & 100.0 & & & \\
\hline total & 234 & 58.5 & 166 & 41.5 & 400 & 100.0 & & & \\
\hline \multicolumn{10}{|l|}{ Education } \\
\hline incomplete basic education* & 77 & 65.3 & 41 & 34.7 & 118 & 100.0 & & & \\
\hline complete basic education & 22 & 62.9 & 13 & 37.1 & 35 & 100.0 & 0.65 & $0.29-1.45$ & 0.297 \\
\hline incomplete university degree & 8 & 47.1 & 9 & 52.9 & 17 & 100.0 & 0.30 & $0.10-0.92$ & 0.036 \\
\hline complete university degree & 5 & 33.3 & 10 & 66.7 & 15 & 100.0 & 0.20 & $0.06-0.69$ & 0.011 \\
\hline total & 234 & 58.5 & 166 & 41.5 & 400 & 100.0 & & & \\
\hline \multicolumn{10}{|l|}{ Contact with cats } \\
\hline yes & 59 & 64.1 & 33 & 35.2 & 92 & 100.0 & 1.68 & $1.09-2.60$ & 0.019 \\
\hline no & 175 & 56.8 & 133 & 43.2 & 308 & 100.0 & & & \\
\hline total & 234 & 58.5 & 166 & 41.5 & 400 & 100.0 & & & \\
\hline
\end{tabular}

* Reference category. OR: odds ratio; CI: confidence interval; IgG: immunoglobulin G.

\section{DIscussion}

This was the first epidemiological study carried out among pregnant and postpartum women in the City of Niterói, State of Rio de Janeiro, Brazil in which the prevalence of $\operatorname{IgG}$ anti-T. gondii antibodies found was $58.5 \%$. In Brazil, this value was similar to results found by other authors in studies on pregnant women in southern Brazil: $59.8 \%$ and $54.8 \%$ in Rio Grande do Sul ${ }^{18,19}, 49.5 \%$ in Minas Gerais ${ }^{17}$ and $55.1 \%$ in Paraná $^{22}$. However, it was lower than what was observed in other states such as Mato Grosso ${ }^{21}$ (70.7\%), Mato Grosso do $\mathrm{Sul}^{27}$ $(91.6 \%)$ and $\operatorname{Goiás}^{23}(67.7 \%)$ and in the indigenous Amazonas population ${ }^{28}(73.5 \%)$. The comparison of the seropositivity of the pregnant women in Niterói with the prevalence of toxoplasmosis in other countries showed that the number of cases found in this study is higher than in Palestine ${ }^{29}(27.9 \%)$, China $^{30}(12.3 \%)$, and Venezuela ${ }^{31}(33 \%)$ and similar to the prevalence found in France $^{32}$ (47\%), Albânia ${ }^{33}$ (48.6\%), and Egypt $^{34}(57.6 \%)$. The results observed in the present study show that in this population a significant number of susceptible women can acquire toxoplasmosis over the course of pregnancy. These susceptible patients present the risk that, through vertical transmission, the parasite may be passed on to the fetus, which could even lead to fetal death. This means that guidance on primary prevention measures and serological monitoring of pregnant women in the at-risk group (seronegative) are important measures for preventing congenital toxoplasmosis.

The prevalence of IgM anti-T. gondii antibodies was $4.2 \%$, but only one patient presented an intermediate result in the IgG avidity test, while the other patients showed high $\operatorname{IgG}$ avidity. In this case, the physician's decision was to begin treatment for congenital toxoplasmosis. However, it is important to take into consideration that a positive IgM result and/or low/intermediate avidity may influence the decision to start treatment. The treatment can be often unnecessary, as a result of an incorrect interpretation of serological results turning the treatment more dangerous than the parasite itself $f^{4,10}$.

Although a large number of women aged 21 to 30 years were found to bepositive, the percentage of women who were seropositive for toxoplasmosis was higher in the age group from 31 to 45 years (66.9\%). The odds of seropositivity among participants in the age group from 31 to 45 years were 3.97 times higher than among other participants, after multivariate analysis. This probably occurred because the women who were in the age group from 31 to 45 years had more chances of contact with the parasite throughout life. This finding reinforces the importance of routine serological screening for pregnant women. This increase in prevalence with age is consistent with the results from previous studies ${ }^{18,19,21-23}$.

Multivariate analysis indicated that pregnant and postpartum women with a low educational level (less than eight years of schooling) showed greater chance of being infected with 
T. gondii. Patients who had completed high school were clearly shown to be protected against anti-T. gondii seropositivity. Several other authors who have studied toxoplasmosis among pregnant women have also found similar results ${ }^{18,22,23,25,35}$. These results show the importance of social and educational investments as preventive measures ${ }^{36}$, not only against toxoplasmosis but also against other diseases. In relation to histories of abortions, there was no significant association between occurrences of previous abortions and seroprevalence for toxoplasmosis $(p=0.212)$. Similar results have also been found in other studies ${ }^{21,37,38}$.

Contact with domestic cats was regularly associated with Toxoplasma gondii transmission. In a study on the importance of farm animals for $T$. gondii infection in Brazil, it was concluded that cats were the key to controlling toxoplamosis ${ }^{39}$. In the present study, a statistically significant association was found between seropositivity for toxoplasmosis and contact with cats $(\mathrm{p}=0.039)$. However, some studies on pregnant women have obtained different results, finding no significant association between seroprevalence and contact with domestic cats ${ }^{19,22,40}$. In contrast, other authors have found an association with the presence of cats $^{25,35}$. It is known that the risk of infection is higher when there is contact with the feces of cats that are eliminating oocysts ${ }^{5,39}$. Proper hygiene measures may decrease the risk of infection, such as correct disposal of cat feces, frequent cleaning of litter boxes and feeding cats with manufactured food or cooked meat ${ }^{5}$. It is important that pregnant women should avoid contact with cat feces and delegate these cleaning tasks to other people.

The presence of rodents at home was reported by 98 (41.8\%) seropositive women. Although there was initially a significant association $(\mathrm{p}=0.008)$ with $T$. gondii infection, this variable ceased to have any significant association with seropositivity for toxoplasmosis after multivariate analysis ( $>0.05$ ). Multiple logistic regression makes a comparison between the variables that best explain the outcome. Thus, the presence of rodents at home was compared with other variables that were entered into the multivariable logistic regression model, such as age, educational level and contact with cats, and was found not to be statistically significantly associated with positivity for $T$. gondii infection in this population. Nonetheless, rodents, along with flies and cockroaches, have been epidemiologically implicated in mechanical transmission of T. gondii oocysts, and may facilitate contamination of food and water ${ }^{25}$. Moreover, cats are commonly present in homes in order to control rodents in peridomestic areas. The cat/rodent combination may be related to transmission of $T$. gondii in humans and animals ${ }^{40}$.

Consumption of raw or undercooked meat has been recognized as an important means of transmission ${ }^{19,20,25,41}$. However, in the present study, it was not associated with infection by $T$. gondii. Similarly, studies in Rolândia ${ }^{22}$, in the State of Paraná, and in Recife ${ }^{42}$, in the State of Pernambuco, Brazil, did not find any association between seropositivity for $T$. gondii and raw meat consumption. These findings may reflect differences in consumers' eating habits, or different prevalences of infection in the meat-producing animals of these regions. There was no statistically significant association between seroprevalence and consumption of dried or cured meat (chorizo, ham, sausages or salami). However, some studies on pregnant women in the State of Rio Grande do Sul, Brazil, showed that women who had the habit of preparing and sometimes tasting sausage meat before it was cooked were at risk of becoming infected with cysts from bradyzoites present in the meat ${ }^{19,40}$. Preparation or consumption of dried or cured meat is not a common practice in the State of Rio de Janeiro, which makes people less susceptible to this source of infection.

Contact with soil was not associated with $T$. gondii infection, although this has been widely cited in the literature as a risk factor for toxoplasmosis ${ }^{19,22,40,43}$. Moreover, the water supply can also be a source of infection by $T$. gondii, acting as a disseminator for oocysts, and contamination of municipal water tanks by the feces of infected cats can lead to outbreaks or epidemics ${ }^{44,45}$. However, in the present study, consumption of untreated water was not associated with infection by $T$. gondii. The urban origin of the pregnant and postpartum women studied and their low level of contact with water and soil, that could be contaminated with oocysts of the parasite, probably places this population at a lower risk of infection through these sources.

The habit of drinking raw (unpasteurized or untreated) milk may be a risk factor for infection with $T$. gondii during pregnancy. It was found that $33(14.1 \%)$ of the seropositive women in this study had the habit of consuming untreated cow's or/and goat's milk. In Europe, 6 to 17\% of pregnant women in different countries have been found to consume untreated milk or its derivatives ${ }^{38}$. In the State of Goiás, Brazil, a study showed that $18.6 \%$ of the pregnant women consumed unpasteurized goats' milk ${ }^{25}$. In Rio Grande do Sul, $8.7 \%$ of the pregnant women reported consuming untreated milk ${ }^{19}$. Milk has been considered to be a potential vehicle for spreading toxoplasmosis in humans, since experimental work has shown that milk from infected animals contains tachyzoites and that this milk is capable of transmitting the infection to these animals' offspring ${ }^{46,47}$.

In relation to garbage disposal, there was no significant difference between seropositive and seronegative pregnant and postpartum women in this study. However, this variable is important because poor sanitary conditions favor transmission of diseases. In the case of toxoplasmosis, accumulation of waste in unsafe locations could favor transmission of oocysts by flies, cockroaches and rats that were attracted to these locations ${ }^{25}$. Thus, lack of garbage collection from homes would be a risk factor for infection. In southern Brazil, some authors ${ }^{40}$ have stated that the garbage in the region that they studied played an important role as a source of infection. In the present study, the patients' hometown (Niterói) has regular public garbage collection and, thus, these women were less exposed to contact with potential vectors of oocysts, like rodents, cockroaches and other insects.

The prevalence of IgG anti-T. gondii antibodies in the City of Niterói was high, $58.5 \%$, and the risk factors for infection, after multivariate analysis, were: age over 30 years, contact with cats and education levels lower than university graduate level. 
The results observed in the present study lead to the conclusion that there is considerable exposure to risk factors in this population and that a significant number of susceptible women can acquire Toxoplasma gondii infection over the course of pregnancy. These susceptible patients present the risk that, through vertical transmission, the parasite may be passed on to the fetus, which could even lead to fetal death. This means that guidance on primary prevention measures and serological monitoring of pregnant women in the at-risk group (seronegative) are important measures for preventing congenital toxoplasmosis and should be implemented within prenatal care.

\section{CONFLICT OF INTEREST}

The authors declare that there is no conflict of interest.

\section{FINANCIAL SUPPORT}

Coordenação de Aperfeiçoamento de Pessoal de Nivel Superior (CAPES), Toxoplasmosis Laboratory of the Oswaldo Cruz Institute, Oswaldo Cruz Foundation, Evandro Chagas Clinical Research Institute, and Federal Fluminense University.

\section{REFERENCES}

1. Coutinho SG, Garcia AP, Amendoeira MRR, Assumpção MR, Albano N. Detection of newborn infants at risk for congenital toxoplasmosis in Rio de Janeiro, Brazil. Rev Inst Med Trop Sao Paulo 1983; 25:25-30.

2. Montoya JG, Liesenfeld O. Toxoplasmosis. Lancet 2004; 363:1965-1976.

3. Thiebaut RS, Leproust S, Chêne G, Glibert R. Effectiveness of prenatal treatment for congenital toxoplamosis: a meta-analysis of individual patients data. Lancet 2007; 369:115-122.

4. Remington JS, McLeod R, Wilson CB, Desmonts G. Toxoplasmosis. In: Remington JS, Klein JO, editors. Infectious diseases of the fetus and newborn infant. $7^{\text {th }}$ ed. Pennsylvania: Elsevier. 2010. p. 918-1041.

5. Jones JL, Lopez A, Wilson M, Schulkin J, Gibbs R. Congenital toxoplasmosis: a review. Obstet Gynecol 2001; 56:296-305.

6. Bichara CNC, Canto GAC, Tostes CL, Freitas JJS, Carmo EL, Póvoa MM, et al. Incidence of congenital toxoplasmosis in the city of Belém, State of Pará, Northern Brazil, determined by a neonatal screening program: preliminary results. Rev Soc Bras Med Trop 2012; 45:122-124.

7. Soares JASS, Carvalho SFG, Caldeira AP. Profile of pregnant women and children treated at a reference center for congenital toxoplasmosis in the Northern State of Minas Gerais, Brazil. Rev Soc Bras Med Trop 2012; 45:55-59.

8. Lago EG, Pitrez PMC. Toxoplasmosis, interdisciplinarity and geography. Sci Med (Porto Alegre) 2010; 20:3-4.

9. Eckert J. Workshop summary: food safety: meat-and fish-borne zoonoses. Vet Parasitol 1996; 64:143-147.

10. Amendoeira MRR, Camillo-Coura LF. A brief review on toxoplasmosis in pregnancy. Sci Med (Porto Alegre) 2010; 20:113-119.

11. Rey L. Toxoplasma gondii e Toxoplasmose. In: Rey L, editor. Parasitologia: parasitos e doenças parasitárias do homem nos trópicos ocidentais. $4^{\text {th }}$ ed. Rio de janeiro: Guanabara Koogan; 2008. p. 192-206.

12. Tenter AM, Heckeroth AR, Weiss LM. Toxoplasma gondii: from animals to humans. Int J Parasitol 2000; 30:1217-1258.

13. Hill D, Dubey JP. Toxoplasma gondii: transmission, diagnosis and prevention. Clin Microbiol Infect 2002; 8:634-640.
14. Dubey JP, Lago EG, Gennari SM, Su C, Jones JL. Toxoplasmosis in humans and animals in Brazil: high prevalence, high burden of disease, and epidemiology. Parasitology 2012; 10:1-50.

15. Nash JQ, Chissel S, Jones J, Warburton F, Verlander NQ. Risk factors for toxoplasmosis in pregnant women in Kent, United Kingdom. Epidemiol Infect 2005; 133:475-483.

16. Santos TR, Costa AJ, Toniollo GH, Luvizotto MCR, Benetti AH, Santos RR, et al. Prevalence of anti- Toxoplasma gondii antibodies in dairy cattle, dogs, and humans from the Jauru micro-region, Mato Grosso state, Brazil. Veterinary Parasitology 2009; 161:324-326.

17. Fonseca AL, Silva RA, Fux B, Madureira AP, Sousa FF, Margonari C. Epidemiologic aspects of toxoplasmosis and evaluation of its seroprevalence in pregnant women. Rev Soc Bras Med Trop 2012; 45:357-364.

18. Varella IS, Wagner MB, Darela AC, Nunes LM, Muller RW. Seroprevalence of toxoplasmosis in pregnant women. J Pediatr (Rio J) 2003; 79:69-74.

19. Cademartori BG, Farias NAR, Brod CS. Seroprevalence and risk factors to Toxoplasma gondii infection in pregnant women of Pelotas, South of Brazil. Rev Panam Infectol 2008;10:30-35.

20. Spalding SM, Amendoeira MRR, Ribeiro LC, Silveira C, Garcia AP, Camillo-Coura L. Prospective study of pregnants and babies with risk of congenital toxoplasmosis in municipal district of Rio Grande do Sul. Rev Soc Bras Med Trop 2003; 36:483-491.

21. Leão PRD, Meirelles Filho J, Medeiros SF. Toxoplasmosis: Seroprevalence in postpartum women attended by SUS (Brazilian Public Health System). Rev Bras Ginecol Obstet 2004; 26:627-632.

22. Dias RCF, Lopes-Mori FMR, Mitsuka-Breganó R, Dias RAF, Tokano DV, Reiche EMV, et al. Factors associated to infection by Toxoplasma gondii in pregnant women attended in basic health units in the city of Rolândia, Paraná, Brazil. Rev Inst Med Trop Sao Paulo 2011; 53:185-191.

23. Sartori AL, Minamisava R, Avelino MM, Martins CA. Prenatal Screening for toxoplamosis and factors associated with seropositivity of pregnant women in Goiânia, Goiás. Rev Bras Ginecol Obstet 2011; 33:93-98.

24. Meirelles Filho J. Toxoplasmose e gravidez: inquérito sorológico em gestantes e seus recém-nascidos na Maternidade-Escola da Universidade Federal do Rio de Janeiro. J Bras Ginecol 1985; 95:393-401.

25. Avelino MM, Campos-Júnior D, Parada JB, Castro AM. Risk factors for Toxoplasma gondii infection in women of childbearing age. Braz J Infect Dis 2004; 8:164-174.

26. Teva A, Fernandez JCC, Silva VL. Imunologia. In: Molinaro EM, Caputo LFG, Amendoeira MRR, editores. Conceitos e métodos para formação de profissionais em laboratórios de saúde. Vol. 4. Rio de Janeiro: EPSJV-IOC; 2009. p. 19-124.

27. Figueiró- Filho EA, Lopes AHA, Senefonte FRA, Souza J, Virgilio G, Botelho CA, et al. Toxoplasmose aguda: estudo da frequência, taxa de transmissão vertical e relação entre os testes diagnósticos materno-fetais em gestantes em Estado da Região Centro-Oeste do Brasil. Rev Bras Ginecol Obstet 2005; 27:442-449.

28. Boia MN, Carvalho-Costa FA, Sodre FC, Pinto GMT, Amendoeira MRR. Seroprevalence of Toxoplasma gondii infection among indian people living in Iauarete, Sao Gabriel da Cachoeira, Amazonas, Brazil. Rev Inst Med Trop 2008; 50:17-20.

29. Nijem KI, Al-Amleh S. Seroprevalence and associated risk factors of toxoplasmosis in pregnant women in Hebron district, Palestine. East Mediterr Health J 2009; 15:1278-1284.

30. Xiao Y, Yin J, Jiang N, Xiang M, Hao L, Lu H, et al. Seroepidemiology of human Toxoplasma gondii infection in China. BMC Infect Dis 2010; 10:4.

31. Diaz-Suarez O, Estevez J. Seroepidemiology of toxoplasmosis in women of childbearing age from a marginal community of Maracaibo, Venezuela. Rev Inst Med Trop 2009; 51:13-17.

32. Fromont EG, Riche B, Rabilloud M. Toxoplasma seroprevalence in a rural population in France: detection of a household effect. BMC Infect Dis 2009; 9:76.

33. Maggi P, Volpe A, Carito V, Schinaia N, Bino S, Basho M, et al. Surveillance of toxoplasmosis in pregnant women in Albania. New Microbiol 2009; 32:89-92.

34. El-Gozamy BR, Mohamed SA, Mansour HA. Toxoplasmosis among pregnant women in Qualyobia Governorate, Egypt. J Egypt Soc Parasitol $2009 ; 39: 389-401$. 
35. Lopes FMR, Mitsuka-Breganó R, Gonçalves DD, Freire RL, Karigyo CJT, Wedy GF, et al. Factors associated with seropositivity for anti- Toxoplasma gondii antibodies in pregnant women of Londrina, Paraná, Brazil. Mem Inst Oswaldo Cruz 2009; 104:378-382.

36. Lopes-Mori FMR, Mitsuka-Breganó R, Capobiango JD, Inoue IT, Reiche EMV, Morimoto HK, et al. Programas de controle da toxoplasmose congênita. Rev Assoc Med Bras 2011; 57:594-599.

37. Garcia G, Sampedro FJ. Seroprevalence of Toxoplasma gondii in pregnant women. Aten Primaria 1995; 16:151-153.

38. Qublan HS, Jumaian NF, Abu-Salem A, Hamadelil FY, Mashagbeh M, Abdel-Ghani F. Toxoplasmosis and habitual abortion. J Obstet Gynaecol 2001; 22:296-298.

39. Millar PR, Sobreiro LG, Bonna ICF, Amendoeira MRR. The importance of food animals in the infection for Toxoplasma gondii in Brazil. Semina Ciências Agrárias 2008; 29:693-706.

40. Spalding SM, Amendoeira MRR, Klein CH, Ribeiro LC. Serological screening and toxoplasmosis exposure factors among pregnant women in South of Brazil. Rev Soc Bras Med Trop 2005; 38:173-177.

41. Cook AJ, Gilbert RE, Buffolano W, Zufferey J, Pertensen E, Jenum PA, et al. Sources of toxoplasma infection in pregnant women: European multicenter case-control study. European Research Network in Congenital Toxoplasmosis. BMJ 2000; 321:142-147.

42. Porto AM, Amorim MM, Coelho IC, Santos LC. Perfil sorológico para toxoplasmose em gestantes atendidas em Maternidade. Rev Assoc Med Bras 2008; 54:242-248.

43. Jumaian NF. Seroprevalence and risk factors for Toxoplasma Infection in pregnant women in Jordan. East Mediterr Health J 2005; 11:45-51.

44. Silveira CAM. Estudo dos fatores de risco In: Silveira CAM, editor. Toxoplasmose - Dúvidas e Controvérsias. $1^{\text {st }}$ ed. Erechim: Edifapes; 2002. p. 57-66.

45. Bahia-Oliveira LMG, Jones JL, Azevedo-Silva J, Alves CCF, Oréfice F, Addiss DG. Highly endemic, waterborne toxoplasmosis in north Rio de Janeiro State, Brazil. Emerg Infect Dis 2003; 9:55-62.

46. Sacks JJ, Roberto RR, Brooks NF. Toxoplasmosis infection associated with raw goat's milk. JAMA 1982; 248:1728-1732.

47. Hiramoto RM, Mayrbaurl-Borges M, Galisteo Jr AJ, Meireles LR, Macre MS, Andrade Jr HF. Infectivity of cysts of the ME-49 Toxoplasma gondii strain in bovine milk and homemade cheese. Rev Saude Publica 2001; 35:113-118. 